\title{
Himpunan Spektrum Real Untuk Masalah Balikan Nilai Eigen Dari Matriks Tak Negatif
}

\author{
Andi Kresna Jaya ${ }^{\dagger}$
}

\begin{abstract}
Abstrak
Pada paper ini akan dibahas representasi geometri dari himpunan spektrum nilai eigen real yang nilai eigen maksimalnya 1 untuk masalah balikan nilai eigen (invers eigenvalues problem). Untuk menunjukkan representasi tersebut akan digunakan sifat invarian dari jumlah konveks matriks stokastik terhadap jumlah konveks spektrum matriks stokastik tersebut. Representasi geometri yang diperoleh hanya pada $R^{n}$ untuk $n$ $=2,3$ dan 4. Sifat invariant di atas juga akan digunakan untuk menunjukkan bahwa sebuah spektrum matriks tak negatif ditulis dalam bentuk vektor $\left(1, \lambda_{2}, \lambda_{3}, \ldots, \lambda_{n}\right)$, maka $\left(1, t \lambda_{2}, t \lambda_{3}, \ldots, t \lambda_{n}\right)$ merupakan spektrum dari sebuah matriks positif untuk $t \in[0,1)$.
\end{abstract}

Keywords: Spektrum, matriks tak negatif, matriks stokastik, jumlah konveks.

\section{Pendahuluan}

Misalkan sebuah vektor $\sigma=\left(\lambda_{1}, \lambda_{2}, \ldots, \lambda_{n}\right)$, maka yang dimaksud dengan masalah balikan nilai eigen (invers eigenvalue problem) adalah mencari beberapa syarat perlu dan cukup agar vektor tersebut dapat dipandang sebagai spektrum atau kumpulan nilai eigen dari sebuah matriks tak negatif [1, 2, 3, 4, 7]. Dalam banyak literatur mengenai masalah balikan nilai eigen ini, para ahli telah mengemukakan syarat perlu dan cukup agar sebuah vektor real dapat dipandang sebagai spektrum matriks tak negatif walaupun peninjauan tersebut hanya bersifat kasus-kasus khusus [2, 3, 4]. Namun untuk vektor real berdimensi $n=2,3$, syarat perlu dan cukup itu telah diberikan [10].

Teorema utama dari matriks tak negatif dan nilai eigennya adalah Teorema PerronFrobenius $[6,10]$ yang menyatakan bahwa jika $A$ matriks ordo $n$ tak negatif dan tak tereduksi, maka $A$ mempunyai nilai eigen $\lambda$ sedemikian sehingga setiap nilai eigen $\lambda_{i}$ untuk $i=1,2$, $\ldots, n$ dari $A$ berlaku $\lambda \geq\left|\lambda_{i}\right|$, vektor karakeristik untuk $\lambda$ adalah vektor positif, dan multiplisitas aljabarnya adalah 1 . Nilai eigen $\lambda$ yang demikian ini disebut nilai eigen maksimal $A$. Pengertian matriks tereduksi sendiri diberikan di [10], yaitu matriks ordo $n$. $A$ disebut tereduksi jika terdapat matriks permutasi P sedemikian sehingga berlaku

$$
A=P^{T}\left[\begin{array}{ll}
B & C \\
0 & D
\end{array}\right] P
$$

dengan $B$ dan $D$ adalah sub matriks bujur sangkar. Matriks $A$ dikatakan tak tereduksi jika tidak terdapat matriks permutasi $P$.

Pembahasan pada makalah ini memberikan bukti positif untuk sebuah problem terbuka (open problem) pada [8], dengan terlebih dahulu menjelaskan beberapa teorema mengenai matriks tak negatif dan masalah balikan nilai eigen. Untuk menunjukkan secara

Staf Pengajar pada Jurusan Matematika FMIPA Universitas Hasanuddin Makassar 
lengkap, akan ditinjau pada matriks yang sifatnya tereduksi dan tak tereduksi untuk matriks stokastik [10], dan sifat invarian jumlah konveksnya. Kemudian di bagian terakhir diberikan representasi geometri khusus pada spektrum real dari matriks tak negatif berorde $n=2,3$ dan 4. Misalkan $N^{n \times n}$ menyatakan himpunan matriks tak negative, dan $P^{n \times n}$ menyatakan himpunan matriks positif. Untuk menyederhanakan persoalan, spektrum real dari matriks tak negatif dapat dipandang sebagai himpunan bagian dari ruang $R^{n}$ sebagai berikut

$$
\begin{aligned}
& Z^{n}=\left\{\left(1, \lambda_{2}, \lambda_{3}, \ldots, \lambda_{n}\right) \in R^{n}:\left|\lambda_{i}\right| \leq 1 \forall i=2,3, \ldots, n\right\}, \\
& N^{n}=\left\{\left(1, \lambda_{2}, \lambda_{3}, \ldots, \lambda_{n}\right) \in Z^{n}: \exists A \in N^{n x n} \ni \sigma(A)=\left(1, \lambda_{2}, \lambda_{3}, \ldots, \lambda_{n}\right)\right\}, \\
& P^{n}=\left\{\left(1, \lambda_{2}, \lambda_{3}, \ldots, \lambda_{n}\right) \in Z^{n}: \exists A \in P^{n x n} \ni \sigma(A)=\left(1, \lambda_{2}, \lambda_{3}, \ldots, \lambda_{n}\right)\right\}
\end{aligned}
$$

dengan $\sigma(A)$ adalah spektrum real matriks $A$.

\section{Matriks Stokastik}

Suatu matriks bujursangkar tak negatif disebut matriks stokastik jika jumlah entrientri setiap barisnya adalah 1 .

Teorema 2.1. Jika A matriks stokastik orde n, maka berlaku pernyataan-pernyataan berikut:

a. Nilai eigen maksimalnya 1.

b. Misal $\boldsymbol{J}$ adalah matriks $n \times n$ yang seluruh entri-entrinya adalah $1, \boldsymbol{A J}=\boldsymbol{J}$.

c. Vektor $\boldsymbol{u}=(1,1, \cdots, 1)$ adalah vektor eigen untuk nilai eigen 1 .

Bukti :

(a) Misalkan $A=\left(a_{i j}\right)$ dan nilai eigen maksimal $A$ adalah $r$, maka $r_{\min } \leq r \leq r_{\max }$ (lihat [10],Ch.2). Karena $r_{\min }=r_{\max }=1$, maka $r=1$.

(b) $\Rightarrow$ Misalkan $A=\left(a_{i j}\right)$, maka untuk setiap $i=1, \ldots, n$ berlaku $\sum_{j-1}^{n} a_{i j}=1$. Misalkan $J=$ $\left(b_{i j}\right)$, dengan $b_{i j}=1, \forall i, j \in\{1, \ldots, n\}$, maka $\boldsymbol{A} \boldsymbol{J}=\left(\sum_{k=1}^{n} a_{i k} b_{k j}\right)=\left(\sum_{k=1}^{n} a_{i k}\right)=\left(d_{i j}\right)$, dengan $d_{i j}=\sum_{k=1}^{n} a_{i k}$ dan untuk setiap $i=1,2, \ldots, n$ berlaku $\sum_{k=1}^{n} a_{i k}=1$, maka matriks $\boldsymbol{A J}=\boldsymbol{J}$.

$\Leftarrow$ Diketahui $\boldsymbol{A} \boldsymbol{J}=\boldsymbol{J}$, dengan $\boldsymbol{J}$ matriks $n \times n$ dengan entri-entri 1 , maka $A \boldsymbol{J}=$ $\left(\sum_{k=1}^{n} a_{i k} b_{k j}\right)=\left(\sum_{k=1}^{n} a_{i k}\right)=\left(1_{i j}\right)$, dengan $1_{i j}=1, \forall i, j \in\{1,2, \ldots, n\}$. Untuk $i=1,2, \ldots$, $n \sum_{k=1}^{n} a_{i k}=1$ adalah jumlah baris matriks $\boldsymbol{A}$, maka $\boldsymbol{A}$ adalah matriks stokastik.

(c) $\Rightarrow$ Diketahui dari poin a) $r=1$, dan misalkan $\boldsymbol{u}$ adalah vektor eigen yang berkorespondensi dengan $r=1$. Misalkan $\boldsymbol{u}=\left(u_{1}, \ldots, u_{n}\right), \boldsymbol{A} \boldsymbol{u}=\left(a_{i j}\right) u^{\prime}=\left(u_{1}, \ldots, u_{n}\right)^{\prime}$, dengan $\sum_{k=1}^{n} a_{i k} u_{k}=u_{i}$, untuk setiap $i=, 2, \ldots, n$. Misalkan $u_{s}=\max \left\{u_{1}, \ldots, u_{n}\right\}$ untuk suatu $s \in\{1, \ldots, n\}$, maka

$$
1=\sum_{k=1}^{n} a_{s k} \frac{u_{k}}{u_{s}}
$$




$$
\begin{aligned}
\sum_{k=1}^{n} a_{s k} & =\sum_{k=1}^{n} a_{s k} \frac{u_{k}}{u_{s}} \\
0 & =\sum_{k=1}^{n} a_{s k}\left(\frac{u_{k}}{u_{s}}-1\right) .
\end{aligned}
$$

$a_{s k} \geq 0$ untuk setiap $\mathrm{k}=1,2, \ldots, n$ dan $\sum_{k=1}^{n} a_{s k}=1$, maka haruslah $\frac{u_{k}}{u_{s}}-1=0$, untuk setiap $k=1,2, \ldots, n . u_{k}=u_{s}$ untuk setiap $k=1,2, \ldots, n$, maka vektor $\boldsymbol{u}=(1,1$, $\ldots, 1)$ adalah vektor eigen yang berkorespondensi dengan nilai eigen 1 .

$\Leftarrow$ Diketahui vektor eigen yang berkorespondensi dengan nilai eigen maksimal 1 adalah $\boldsymbol{u}=(1,1, \ldots, 1)$, untuk $A$. Misalkan $A=\left(a_{i j}\right), \forall i, j \in\{1,2, \ldots, n\}$, atau

$$
\begin{gathered}
\boldsymbol{A u}=\left(a_{i j}\right) \boldsymbol{u} \\
=\boldsymbol{u}
\end{gathered}
$$

Maka jumlah entri-entri dalam setiap baris matriks $\boldsymbol{A}$ adalah 1, atau $\boldsymbol{A}$ adalah matriks stokastik.

Teorema 2.2. Misalkan $\boldsymbol{A}$ dan $\boldsymbol{B}$ adalah dua matriks stokastik, maka

a. $\boldsymbol{A} \boldsymbol{B}$ adalah matriks stokastik

b. Untuk $\theta \in[0,1)$, maka $\theta \boldsymbol{A}+(1-\theta) \boldsymbol{B}$ adalah matriks stokastik.

\section{Bukti :}

(a) Misalkan $\boldsymbol{A}$ dan $\boldsymbol{B}$ adalah matriks stokastik, dengan menggunakan sifat (b) pada Teorema 2.1, maka $(\boldsymbol{A B}) \boldsymbol{J}=\boldsymbol{A}(\boldsymbol{B} \boldsymbol{J})=\boldsymbol{A J}=\boldsymbol{J}$, diperoleh $(\boldsymbol{A B}) \boldsymbol{J}=\boldsymbol{J}$ maka $\boldsymbol{A B}$ adalah matriks stokastik.

(b) Pembuktian dengan memakai poin (b) pada Teorema 2.1, dan misalkan $\boldsymbol{A}$ dan $\boldsymbol{B}$ adalah matriks stokastik, maka untuk setiap $\theta \in[0,1]$ berlaku

$$
\begin{aligned}
(\theta \boldsymbol{A}+(1-\theta) \boldsymbol{B}) \boldsymbol{J} & =\theta \boldsymbol{A} \boldsymbol{J}+(1-\theta) \boldsymbol{B} \boldsymbol{J} \\
& =\theta \boldsymbol{J}+(1-\theta) \boldsymbol{J}=\boldsymbol{J}
\end{aligned}
$$

maka $\theta \boldsymbol{A}+(1-\theta) \boldsymbol{B}$ matriks stokastik untuk $\theta \in(0,1]$.

Misalkan $Z_{1}, Z_{2}, \ldots, Z_{k}$ adalah bilangan-bilangan dalam bidang kompleks, dan $\alpha_{1}, \alpha_{2}, \ldots, \alpha_{k}$ adalah bilangan tak negatif yang jumlah keseluruhannya 1, maka titik $Z=\sum_{i=1}^{k} \alpha_{i} Z_{i}$ disebut jumlah konveks dari $Z_{1}, Z_{2}, \ldots, Z_{k}$. Sifat ini kemudian akan dikembangkan dalam dua akibat berikut.

Akibat 2.1. Jika $\lambda$ adalah nilai eigen dari matriks stokastik $\boldsymbol{A}$ berorde $n$ dan $\gamma$ adalah jumlah konveks dari $1, \lambda, \lambda^{2}, \ldots, \lambda^{n}$, untuk $\sum_{i=0}^{k} c_{i}=1, c_{i} \geq 0$, maka $\gamma$ adalah nilai eigen dari matriks stokastik $\boldsymbol{B}=c_{0} \boldsymbol{I n}+c_{1} \boldsymbol{A}+c_{2} \boldsymbol{A}^{2}+\ldots+c_{k} \boldsymbol{A}^{k}$.

Akibat 2.2. Jika $\lambda$ nilai eigen dari matriks stokastik $\boldsymbol{A}$ berordo $n$, maka untuk sembarang bilangan tak negatif $c<1, c \lambda$ nilai eigen dari matriks stokastik.

Kedua akibat di atas telah diberikan bukti di [1]. Selanjutnya Perhatikan bentuk matriks $\boldsymbol{J}$ dengan entri-entrinya 1 , nilai karakteristik dari $\boldsymbol{J}$ adalah $n$ dan 0 , atau spektrumnya adalah ( $n$, 
$0, \ldots, 0)$. Jika dikalikan dengan skalar $1 / n$ maka matriks $J_{n}=\frac{1}{n} J$ adalah matriks stokastik dengan spektrumnya adalah $(1,0, \ldots, 0)$. Teorema berikut merupakan rangkuman Akibat 2.1 dan Akibat 2.2.

Teorema 2.3. Jika $\sigma(\boldsymbol{A})=\left(1, \lambda_{2}, \ldots, \lambda_{n}\right)$ adalah spektrum matriks stokastik $\boldsymbol{A}$, maka $\boldsymbol{B}=\theta A$ $+(1-\theta)$ Jn adalah matriks stokastik dengan spektrum $\sigma(B)=\left(1, \theta \lambda_{2}, \ldots, \theta \lambda_{n}\right)$ untuk setiap $0 \leq \theta \leq 1$.

\section{Bukti :}

Untuk $0 \leq \theta \leq 1$, pandang jumlah konveks matriks $\boldsymbol{A}$ dengan $\boldsymbol{J}_{n}, \boldsymbol{B}=\theta \boldsymbol{A}+(1-\theta) \boldsymbol{J}_{n}$, maka dengan Teorema 2.2 poin (b), $B$ adalah matriks stokastik. Diketahui $\boldsymbol{J}_{\boldsymbol{n}}$ matriks stokastik dengan spektrum $(1,0, \ldots, 0)$, maka terdapat $\boldsymbol{P}$ matriks tak singulir sedemikian sehingga $P \boldsymbol{J} \boldsymbol{n} P^{-1}=\operatorname{diag}(1,0, \ldots, 0)$. Sehingga

$$
\begin{gathered}
P B P^{-1}=P \theta A P^{-1}+P(1-\theta) J_{n} P^{-1}=\theta P A P^{-1}+(1-\theta) P J_{n} P^{-1} \\
=\theta P A P^{-1}+(1-\theta) \operatorname{diag}(1,0, \ldots, 0)
\end{gathered}
$$

dengan $\boldsymbol{P} \boldsymbol{B} \boldsymbol{P}^{-1}$ similar dengan $\boldsymbol{B}$ dan $\boldsymbol{P} \boldsymbol{A} \boldsymbol{P}^{-1}$ similar dengan $\boldsymbol{A}$. Misalkan

$$
\boldsymbol{P A P}^{-1}=\left[\begin{array}{cccc}
d_{11} & d_{12} & \cdots & d_{1 n} \\
d_{21} & d_{22} & \cdots & d_{2 n} \\
\vdots & \vdots & \vdots & \vdots \\
d_{n 1} & d_{n 2} & \cdots & d_{n n}
\end{array}\right]
$$

Klaim: Spektrum matriks $B$ adalah $\left(1, \theta \lambda_{2}, \ldots, \theta \lambda_{n}\right)$. Misalkan $C=\operatorname{diag}\left(1, \theta \lambda_{2}, \ldots, \theta \lambda_{n}\right)$, maka

$$
\boldsymbol{P} \boldsymbol{B} \boldsymbol{P}^{-1}-\boldsymbol{C}=\theta \boldsymbol{P} \boldsymbol{A} \boldsymbol{P}^{\mathbf{1}}+(1-\theta) \operatorname{diag}(1,0, \ldots, 0)-\boldsymbol{C}
$$

$$
=\left[\begin{array}{cccc}
\theta d_{11}+(1-\theta)-1 & \theta d_{12} & \cdots & \theta d_{1 n} \\
\theta d_{21} & \theta d_{22}-\lambda_{2} & \cdots & \theta d_{2 n} \\
\vdots & \vdots & \ddots & \vdots \\
\theta d_{n 1} & \theta d_{n 2} & \cdots & \theta d_{n n}-\lambda_{n}
\end{array}\right]
$$

$$
\begin{aligned}
\boldsymbol{P B P}^{-1}-\boldsymbol{C} & =\left[\begin{array}{cccc}
\theta d_{11}-\theta & \theta d_{12} & \cdots & \theta d_{1 n} \\
\theta d_{21} & \theta d_{22}-\theta \lambda_{2} & \cdots & \theta d_{2 n} \\
\vdots & \vdots & \ddots & \vdots \\
\theta d_{n 1} & \theta d_{n 2} & \cdots & \theta d_{n n}-\theta \lambda_{n}
\end{array}\right] \\
& =\theta\left[\begin{array}{cccc}
d_{11}-1 & d_{12} & \cdots & d_{1 n} \\
d_{21} & d_{22}-\lambda_{2} & \cdots & d_{2 n} \\
\vdots & \vdots & \ddots & \vdots \\
d_{n 1} & d_{n 2} & \cdots & d_{n n}-\lambda_{n}
\end{array}\right] \\
& =\theta\left(P A P^{-1}-\operatorname{diag}\left(1, \lambda_{2}, \ldots, \lambda_{n}\right)\right)
\end{aligned}
$$

Akan ditunjukkan determinan $\boldsymbol{P} \boldsymbol{B} \boldsymbol{P}^{-\mathbf{1}}-\boldsymbol{C}=\mathbf{0}$. 


$$
\operatorname{det}\left(\boldsymbol{P B} \boldsymbol{P}^{-1}-\boldsymbol{C}\right)=\theta^{n} \operatorname{det}\left(\boldsymbol{P A} \boldsymbol{P}^{-1}-\operatorname{diag}\left(1, \lambda_{2}, \ldots, \lambda_{n}\right)\right)
$$

Karena $\left(1, \lambda_{2}, \ldots, \lambda_{n}\right)$ adalah spektrum matriks $A$, maka $\left(1, \lambda_{2}, \ldots, \lambda_{n}\right)$ juga spektrum dari $\boldsymbol{P A} \boldsymbol{P}^{-1}$. Jadi $\operatorname{det}\left(\boldsymbol{P A} \boldsymbol{P}^{-1}-\operatorname{diag}\left(1, \lambda_{2}, \ldots, \lambda_{n}\right)\right)=0$, maka $\operatorname{det}\left(\boldsymbol{P} \boldsymbol{A} \boldsymbol{P}^{-1}-\boldsymbol{C}\right)=0$. Spektrum dari matriks $\boldsymbol{P} \boldsymbol{B} \boldsymbol{P}^{-1}$ adalah $\left(1, \theta \lambda_{2}, \ldots, \theta \lambda_{n}\right)$. Jadi spektrum $\boldsymbol{B}$ adalah $\sigma(\boldsymbol{B})=\left(1, \theta \lambda_{2}, \ldots, \theta \lambda_{n}\right)$ untuk setiap $0 \leq \theta \leq 1$.

Untuk sembarang matriks tak negatif dengan nilai eigen maksimal 1 yang akan dibahas pada bab berikut, senantiasa terdapat matriks stokastik yang similar dengan matriks tersebut dan dituangkan dalam teorema berikut.

Teorema 2.4. Jika A matriks tak negatif dengan nilai karakteristik maksimal $r$ dan suatu vektor karakteristik positif untuk nilai karakteristik $r$, maka $\boldsymbol{r}^{-1} \boldsymbol{A}$ serupa secara diagonal dengan suatu matriks stokastik.

\section{Bukti}

Misalkan $x=\left(x_{1}, x_{2}, \ldots, x_{n}\right)$ adalah vektor karakteristik positif untuk nilai karakteristik maksimal $r$ dari $\boldsymbol{A}$. Jika $\boldsymbol{D}=\operatorname{diag}\left(x_{1}, x_{2}, \ldots, x_{n}\right)$, maka $\boldsymbol{x}=\boldsymbol{D} \boldsymbol{u}$ dengan $\boldsymbol{u}=(1,1, \ldots, 1)$

$$
\begin{aligned}
\boldsymbol{D}^{-1}\left(r^{-1} \boldsymbol{A}\right) \boldsymbol{D} & =r^{-1} \boldsymbol{D}^{-1} \boldsymbol{A D} \\
\left(r^{-1} \boldsymbol{D}^{-1} \boldsymbol{A} \boldsymbol{D}\right) \boldsymbol{u} & =r^{-1} \boldsymbol{D}^{-1} \boldsymbol{A} \boldsymbol{x} \\
& =r^{-1} D^{-1} r x \\
& =D^{-1} x \\
& =u
\end{aligned}
$$

Maka dengan Teorema 2.2, $r^{-1} D^{-1} A D$ adalah matriks stokastik

\section{Himpunan Spektrum Real Matriks tak Negatif}

Permasalahan yang akan dibahas dalam makalah ini adalah pertanyaan pada paper Alberto Borobia dan Julio Moro [8]. Apakah benar jika $\left(1, \lambda_{2}, \ldots, \lambda_{n}\right)$ spektrum matriks tak negatif (yang tidak similar dengan sembarang matriks positif), maka terdapat dua komponen di $\Lambda=\left\{1, \lambda_{2}, \ldots, \lambda_{n}\right\}$ yang sama, atau terdapat suatu subset $\left\{\gamma_{1}, \ldots, \gamma_{s}\right\}$ dari $\Lambda$ sehingga $\gamma_{1}+\ldots+\gamma_{s}=0$. Untuk itu akan kembali diperhatikan himpunan-himpunan $N^{n}$ dan $P^{n}$ yang telah didefinisikan di awal makalah ini.

Teorema 3.1. Jika $\left(1, \lambda_{2}, \lambda_{3}, \ldots, \lambda_{n}\right) \in N^{n}$, maka untuk setiap $t \in[0.1)$ berlaku $\left(1, t \lambda_{2}, t \lambda_{3}, \ldots, t \lambda_{n}\right) \in P^{n}$.

\section{Bukti :}

Misal $\left(1, \lambda_{2}, \ldots, \lambda_{n}\right) \in N^{n}$, maka terdapat matriks $\boldsymbol{A}$ yang tak negatif dengan spektrum $\sigma(\boldsymbol{A})$ $=\left(1, \lambda_{2}, \ldots, \lambda_{n}\right)$. Sehingga untuk matriks $\boldsymbol{A}$ tersebut ada 2 kasus, yaitu :

1. Jika $\boldsymbol{A}$ matriks tak tereduksi, maka untuk setiap $t$ di dalam $[0,1)$, maka matriks $\boldsymbol{P}=t \boldsymbol{S}$ $+(1-t) \boldsymbol{J n}$ adalah matriks positif dengan spektrum $\sigma(\boldsymbol{P})=\left(1, \lambda_{2}, \ldots, \lambda_{n}\right)$.

2. Jika $\boldsymbol{A}$ adalah matriks tereduksi, maka terdapat matriks permutasi $\boldsymbol{P}$ sedemikian sehingga 


$$
\boldsymbol{P A P}^{T}=\left[\begin{array}{ccccc}
A_{1} & B_{12} & B_{13} & \cdots & B_{1 S} \\
0 & A_{2} & B_{23} & \cdots & B_{2 S} \\
\vdots & \vdots & \ddots & \vdots & \vdots \\
0 & \cdots & \cdots & A_{K-1} & B_{K-1, S} \\
0 & \cdots & \cdots & 0 & A_{K}
\end{array}\right]
$$

$A_{1}, \ldots, A_{k}$ adalah matriks tak tereduksi, di mana $k \leq n$. Pilih matriks tak negatif $\boldsymbol{G}$, yaitu:

$$
\boldsymbol{G}=\left[\begin{array}{cccc}
A_{1} & 0 & \cdots & 0 \\
0 & A_{2} & \cdots & 0 \\
\vdots & \vdots & \ddots & \vdots \\
0 & \cdots & 0 & A_{K}
\end{array}\right]
$$

maka spektrum $\boldsymbol{G}$ adalah $\sigma(\boldsymbol{G})=\left(1, \lambda_{2}, \ldots, \lambda_{n}\right) . \boldsymbol{S}_{k}=D_{K}^{-1} \boldsymbol{A}_{k} D_{k}$ adalah matriks stokastik $n_{k} \times n_{k}$ yang similar dengan $\boldsymbol{A}_{k}$, dan $D_{k}=\operatorname{diag}\left(w_{1 k}, w_{2 k}, \ldots, w_{n k}\right)$. Untuk setiap $i=1, \ldots, k-1$, $A_{i}$ adalah matriks tak negatif $n_{i} \times n_{i}$ yang tak tereduksi (diketahui: $n_{1}+\ldots+n_{k}=n$ ). Misalkan nilai karakteristik maksimal $A_{i}$ adalah $\lambda_{p i}$ untuk suatu $p_{i} \in\{2, \ldots, n\}$, maka terdapat $u=\left(u_{1 i}, \ldots, u_{n i}\right)$ vektor positif yang berkorespondensi dengan nilai karakteristik $\lambda_{p i}$, maka $\lambda_{p i}^{-1} D_{i}^{-1} A_{i} D_{i}=S_{i}$, dengan $D_{i}=\operatorname{diag}\left(u_{1 i}, \ldots, u_{n i}\right)$ dan $S i$ adalah matriks stokastik $\left(n_{i}\right) \times\left(n_{i}\right)$. Bentuk matriks $G$ dapat ditulis menjadi

$$
\left[\begin{array}{cccc}
D_{1} \lambda_{p 1} S_{1} D_{1}^{-1} & 0 & 0 & \\
\vdots & \ddots & \vdots & \vdots \\
0 & \cdots & D_{k-1} \lambda_{p k} S_{k-1} D_{k-1}^{-1} & 0 \\
0 & \cdots & 0 & D_{k} S_{k} D_{k}^{-1}
\end{array}\right]
$$

yang dapat dipisahkan dalam perkalian tiga matriks berikut.

$$
\begin{gathered}
G=D\left[\begin{array}{cccc}
\lambda_{p 1} S_{1} & 0 & \cdots & 0 \\
\vdots & \ddots & \vdots & \vdots \\
0 & \cdots & \lambda_{p k-1} S_{k-1} & 0 \\
0 & \cdots & 0 & S_{k}
\end{array}\right] D^{-1}, \text { dengan } D \\
=\left[\begin{array}{ccc}
D_{1} & \cdots & 0 \\
\vdots & \ddots & \vdots \\
0 & \cdots & D_{k}
\end{array}\right] .
\end{gathered}
$$

Matriks

similar dengan matriks $G$.

$$
\left[\begin{array}{cccc}
\lambda_{p 1} S_{1} & 0 & \cdots & 0 \\
\vdots & \ddots & \vdots & \vdots \\
0 & \cdots & \lambda_{p k-1} S_{k-1} & 0 \\
0 & \cdots & 0 & S_{k}
\end{array}\right]
$$

Pandang matriks stokastik berikut. 


$$
S=\left[\begin{array}{cccc}
\lambda_{p 1} S_{1} & E_{1} & \cdots & 0 \\
\vdots & \vdots & \vdots & \vdots \\
0 & \cdots & \lambda_{p k-1} S_{k-1} & E_{k-1} \\
0 & \cdots & 0 & S_{k}
\end{array}\right]
$$

untuk $i=1, \ldots, k-1, \boldsymbol{E}_{i}$ adalah matriks berukuran $n_{i} \times n_{i+1}$ yang berbentuk

$$
E_{i}=\left[\begin{array}{cccc}
1-\lambda_{p i} & 0 & \cdots & 0 \\
\vdots & \vdots & \vdots & \vdots \\
1-\lambda_{p i} & 0 & \cdots & 0
\end{array}\right]
$$

$S$ adalah matriks stokastik $n \times n$ dengan spektrum, maka $\left\{1, \lambda_{2}, \ldots, \lambda_{n}\right\}$ dengan cara yang sama dengan kasus $\boldsymbol{A}$ yang tak tereduksi, matriks $\boldsymbol{P}=t \boldsymbol{S}+(1-t) \boldsymbol{J n}$ adalah matriks positif $n \times n$ dengan spektrum $\sigma(\boldsymbol{P})=\left(1, t \lambda_{2}, t \lambda_{3}, \ldots, t \lambda_{n}\right)$. Jadi $\left(1, t \lambda_{2}, t \lambda_{3}, \ldots, t \lambda_{n}\right) \in P^{n}$.

Kemudian pandang himpunan $B^{n}=N^{n}-P^{n}$. Himpunan $B^{n}$ merupakan batas himpunan $N^{n}$. Misalkan $\left(1, \lambda_{2}, \lambda_{3}, \ldots, \lambda_{n}\right) \in B^{n}$, maka $\left(1, \lambda_{2}, \lambda_{3}, \ldots, \lambda_{n}\right)$ adalah spektrum dari $\boldsymbol{A}$ matriks tak negatif dan tidak ada satupun matriks positif yang similar dengan $\boldsymbol{A}$. Contohnya, $(1,1, \ldots$, 1) dan $\left(1, \lambda_{2}, \lambda_{3}, \ldots, \lambda_{n}\right)$ sedemikian sehingga $1+\lambda_{2}+\ldots+\lambda_{n}=0$, merupakan spektrum dari matriks tak negatif tapi bukan spektrum matriks positif manapun.

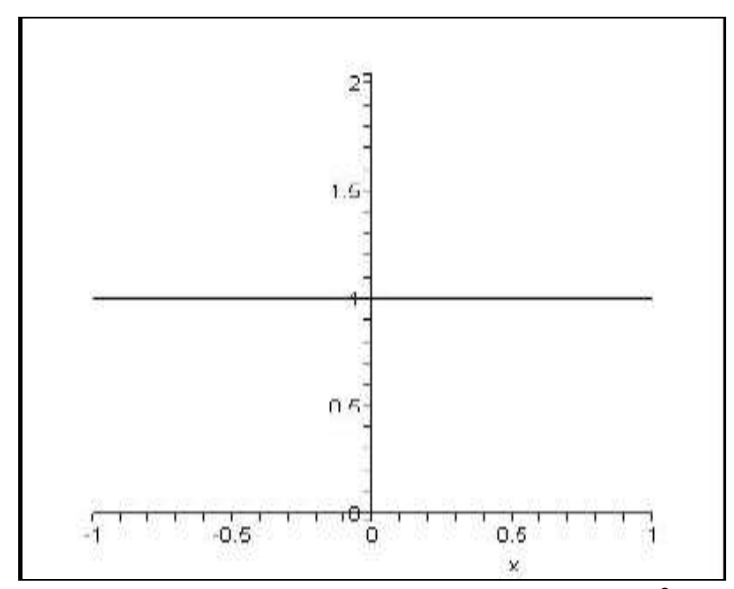

Gambar 1. Representasi Himpunan $N^{2}$.

Perhatikan jika $\left(1, \lambda_{2}\right) \in N^{n}$, maka untuk $\lambda_{2}=1$ atau $\lambda_{2}=-1$, vektor $\left(1, \lambda_{2}\right)$ adalah titik pada batas atau tidak ada matriks positif yang spektrumnya adalah $\left(1, \lambda_{2}\right)$. Nilai-nilai $\lambda_{2}$ hanya terletak pada interval $[-1,1]$. Himpunan $N^{2}$ adalah segmen garis yang berada satu satuan ke atas dari sumbu $-\lambda_{2}$, sebagaimana yang diperlihatkan pada Gambar 1 di atas. Untuk Himpunan $N^{3}$ di Ruang $R^{3}$, himpunan tersebut adalah sebuah bidang yang terletak pada $\lambda_{1}=$ 1 yang dibatasi oleh garis $\lambda_{2}+\lambda_{3}=-1, \lambda_{2}=1, \lambda_{3}=1, \lambda_{2}=-1$, dan $\lambda_{3}=-1$, sebagaimana yang diberikan pada Gambar 2 berikut. 


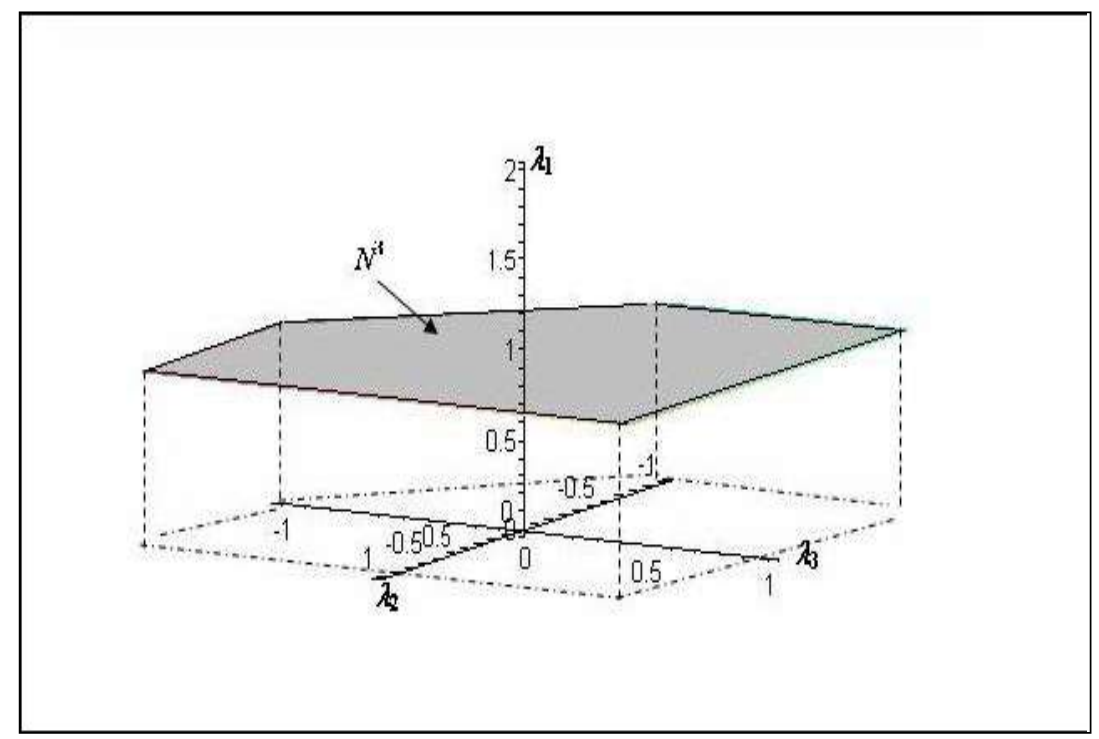

Gambar 2. Representasi Himpunan $N^{3}$.

Untuk himpunan $N^{4}$ di ruang $R^{4}$, himpunannya adalah volume ruang yang berbentuk kubus terpotong oleh persamaan bidang $\lambda_{2}+\lambda_{3}+\lambda_{4}=0$. Namun untuk memberikan bentuk geometrisnya agak sulit dilakukan, sehingga tampilan grafiknya belum diberikan dalam makalah ini.

\section{Penutup}

Untuk $n=2$, pertanyaan pada [8] terjawab secara trivial, yaitu batas himpunan $N^{2}$ adalah $(1,1)$ dan $(1,-1)$. Untuk $n=3$, bidang yang dibatasi oleh $\lambda_{2}+\lambda_{3}=-1, \lambda_{2}=1, \lambda_{3}=1$, $\lambda_{2}=-1$, dan $\lambda_{3}=-1$ di atas bidang $\lambda_{2} O \lambda_{3}$ sejauh 1 satuan. Titik $(1,0,0, \ldots, 0)$ di Ruang $R^{n}$ adalah unsur $P^{n}$, dan setiap kita menarik garis lurus ke sembarang titik pada batas himpunan $N^{n}$, maka titik-titik yang kita peroleh senantiasa unsur dalam $P^{n}$. Akibatnya, bentuk pertanyaan tadi harus lebih spesifik jika $\left(1, \lambda_{2}, \ldots, \lambda_{n}\right)$ spektrum matriks tak negatif (yang tidak similar dengan sembarang matriks positif), maka terdapat $i=2,3, \ldots, n$ sedemikian sehingga $\lambda_{i}=1$. Sebaliknya tidak selalu benar bahwa terdapat suatu subset $\left\{\gamma_{1}, \ldots, \gamma_{s}\right\}$ dari $\Lambda$ sehingga $\gamma_{1}+\ldots+\gamma_{s}=0$, maka $\left(1, \lambda_{2}, \ldots, \lambda_{n}\right)$ spektrum matriks tak negatif (yang tidak similar dengan sembarang matriks positif).

Open problem yang muncul adalah spesifikasi pertanyaan tersebut menjadi : "Apakah benar jika $\left(1, \lambda_{2}, \ldots, \lambda_{n}\right)$ spektrum matriks tak negative (yang tidak similar dengan sembarang matriks positif), maka terdapat $i=2,3, \ldots, n$ sedemikian sehingga $\lambda_{i}=1$, atau $1+\lambda_{2}+\lambda_{3}+\ldots+\lambda_{n}=0$ ?" Di sini telah diperlihatkan, dan demikian pula di [1,2], bahwa untuk $n=2,3$ dan 4, maka jawaban permasalahan pada open problem adalah positif.

\section{Daftar Pustaka}

[1] KresnaJaya, A., 2001, "Masalah nilai karakteristik invers real tak negative", Thesis, Magister Matematika ITB.

[2] Wuwen, G., 1996, "An inverse eigenvalue problem for nonnegative matrices", Linear Algebra and Its Applications, 249, pp : 67-78. 
[3] Radwan, N., 1996, "An inverse eigenvalue problem for symmetric and normal matrices", Linear Algebra and Its Applications, 248, pp : 101-109.

[4] Fiedler, M., 1974, "Eigenvalues of non negative symmetric matrices", Linear Algebra and Its Applications, 9, pp : 119-142.

[5] Kellogg, R.B., 1971, "Matrices similar to a positive or essentially positive matrix", Linear Algebra and Its Applications, 4, pp :191-204.

[6] Marcus, M. \& Minc, H., 1964, "Matrix Theory and Matrix Inequalities", Allyn and Bacon Inc., Boston.

[7] Borobia, A. and Moro, J., 1997, "On non negative matrices similar to positive matrices", Linear Algebra and Its Applications, 266, pp : 365-379.

[8] Borobia, A. and Moro, J., 1998, "On the boundary of the set of real spectra of nonnegative matrices", Linear Algebra and Its Applications, 278, pp : 287-293.

[9] Borobia, A., 1998, "On the nonnegative eigenvalue problem", Linear Algebra and Its Applications, 223/224, pp : 93-97.

[10] Minc, H., 1998, "Nonnegative Matrices", John Wiley-Interscience Publication, New York. 